\title{
A new voice for European neuroscience
}

Despite the scale and vigor of its research activities, Europe has until now lacked a focus for neuroscience that could compare to the American-based Society for Neuroscience (SFN) and its gargantuan annual meeting. In the past, linguistic, cultural and practical barriers have all made trans-national integration much more difficult for European researchers than for their colleagues in the United States. This situation is now changing, however, and the turning point will probably be seen as the European Neuroscience Association (ENA) forum meeting that took place last month in Berlin. Comparisons with the SFN are inevitable, and for the first time the European meeting has emerged as a serious rival, if not in scale at least in terms of quality, diversity and frenetic energy, to its American counterpart.

The ENA has met biannually, but attendance has been stagnant in recent years, due in large part to a lack of coordination with national societies and with the many specialized trans-European meetings which have been competing for attendance with the ENA forum. This year, however, the ENA meeting has been totally revamped, through a combination of better organization and publicity, student discounts, and the help of outside sponsors (including Nature Neuroscience). The result has been a far stronger event, with some 2500 presentations and a total attendance exceeding 4000 (a third of them students). Participants came from all over Europe, and North America was also represented both by speakers and by poster presenters (often European) from American labs. The meeting culminated in the formation of a new body, the Federation of European Neuroscience Societies (FENS), which will replace the ENA and which seems set to emerge as the 'official' voice of neuroscience in Europe.

FENS is an umbrella organization, currently based in Holland, which includes 31 of the major European national and trans-national associations. In joining FENS, the individual associations not only contribute financial resources but also declare their intention to cooperate in forging a sense of community among European researchers. By suspending their own meetings every second year, they will avoid inter-country competition and instead promote the international meeting, starting with Brighton, UK in 2000 and rotating among member countries thereafter. In addition to running the biannual meeting, FENS will likely become the new publisher of the European Journal of Neuroscience, which it may eventually make available online to all its members. It also plans to organize summer and winter schools beginning next year, and hopes in the longer term to sponsor studentships and postdoctoral fellowships. Much will depend on its ability to attract funding support from national governments or from the EC, which in turn will depend on replacing the present cacophony with a united front in which a single organization speaks for the entire neuroscience community. Like the SFN in the United States, FENS expects eventually to play a significant role in lobbying governments on behalf of the research community, and in promoting public awareness of science.

The organizers of the Berlin meeting estimate the number of neuroscientists in Europe at around 50,000, making it comparable in size to the United States. The success of FENS in representing this emerging community will depend on its ability to balance the dominant influence of the wealthy nations of Western Europe with the desire for inclusiveness and representation of less scientifically developed countries, especially in the East. It will also be important to attract international support for the biannual meeting, particularly from American researchers but also from those in other countries such as Japan. Judging from progress so far, it will probably be well worth the trip. 